\title{
People with Asperger's syndrome lead the way in how to work in a group
}

\author{
Jackie Martin ${ }^{1}$, Katrina Fox ${ }^{2}$, \\ Duncan MacGregor ${ }^{2}$ and Laura Hickman ${ }^{2}$
}

\begin{abstract}
Summary: This article is written about and by a group of three adults diagnosed with Asperger's syndrome and one neuro-typical person (neuro-typical refers to someone who does not have Asperger's syndrome or autism). The group has called itself the Asperger's Consultation Group and was formed in 2010 with the aim of conducting a piece of research to identify how adults with Asperger's syndrome felt about the services they received. The group was initially formed as part of a PhD project. The group has now expanded beyond this and continues to meet. The group members are Katrina, Laura, Duncan and Jackie. Katrina, Laura and Duncan have been formally diagnosed with Asperger's syndrome.
\end{abstract}

Keywords: Asperger's syndrome; groupwork; group work ; user led groups; research; group values

1. Principal Lecturer in Social Work, De Montfort University

2. Members of the Asperger's Consultation Group

Address for correspondence: Jackie Martin,JMartin02@dmu.ac.uk

Date of first (online) publication: 
Jackie Martin, Katrina Fox, Duncan MacGregor and Laura Hickman

\section{Asperger's syndrome as conventionally viewed}

Asperger's syndrome, along with autism is typically characterised by the triad of impairments 'in the skills of social interaction, communication and imagination' (Wing, 1991, p. 115). People with Asperger's syndrome are said to have difficulty forming relationships with 'social impairment' being the criteria which should primarily be met to receive a diagnosis of Asperger's syndrome (Attwood, 2007). Given this view of people with Asperger's syndrome, it seems unlikely that a group of individuals with Asperger's syndrome would be able to meet regularly over a sustained period of three years, work together on a research project and interact in the most positive and supportive manner with each other at all times. A 'Google' and 'GoogleScholar' search for 'groupwork and Asperger's syndrome' and 'groupwork and autism' revealed results about interventions and techniques of including students in the classroom, but no other obvious examples of groups consisting of adults with Asperger's syndrome working successfully together. That is not to say that there aren't any, just that we are not aware of any publications about them. The motivation for writing this article is to address this and it is written to tell others about what adults with Asperger's syndrome can and have achieved and to reflect on how and why the group has been so successful.

\section{The group members' views of Asperger's syndrome}

People with Asperger's syndrome are often said to lack or be delayed in developing 'theory of mind'. This refers to the ability to perceive what someone else is thinking (Baron-Cohen, 1995). This is said to make it more difficult to relate to others and so should make working in a group more difficult.

Group members have their own views on conventional ways of thinking about Asperger's syndrome:

Duncan: As far as theory of mind goes, I agree with it but I know I definitely have imagination. I think good communication can be learnt and I now feel proficient in this. For me, my own research following my diagnosis gave me some answers when I looked at the triad of impairment-I could see where I was going wrong but also why I was going wrong. 
Katrina: In my opinion the conventional views surrounding Asperger's syndrome are far too narrow and restricted, much of the information made available to me when I was diagnosed aged 21 was concerned only with the medical side of Asperger's and seemed to focus solely on my 'impairments'. This led to me doubting my abilities and left me feeling useless. I have found that conventional views don't take into consideration individual differences and instead seem to adopt a 'one size fits all' policy which in all walks of life is never the case. This combination of feeling useless and feeling defined by my inadequacies led me to feel depressed and I developed an extremely negative viewpoint about myself. In my experience I have found the conventional perceptions of Asperger's syndrome to be very damaging to self esteem and it is only after several years of confusion that I am started to understand that I don't have to fit into a certain profile. The conventional view of Asperger's syndrome gives the impression that effective and, more importantly, enjoyable groupwork would be impossible. The work that the Asperger's Consultation group has done defies this idea as together we have achieved what we thought was impossible and we enjoyed ourselves and learnt a lot about ourselves throughout the process.

Laura: I think the triad of impairment is correct but not necessarily all of it. Just because you've got Asperger's doesn't mean that everyone is the same.

The group has operated on the basis that Asperger's syndrome is a difference, rather than a deficit. Individual members struggle in some areas but have real strengths in others.

Duncan: For me, it is not being able to 'read' people. It can take me a while to understand what people are saying. I am very literal in my understanding. Asperger's gift to me has been my ability with mathematics and an analytical mind.

Katrina: I find defining my feelings towards having Asperger's syndrome rather difficult. Some days I feel it provides me with extraordinary talents and I feel content with my situation. Other days I feel that it holds me back and prevents me from achieving my life goals. Every day is different but my overall opinion is that Asperger's syndrome is a disability because even on the very good days there are things that it prevents me from doing. Life is difficult and tiring and when I was first diagnosed I felt as though my life had been stolen from me. I was disappointed that things would always be so difficult, I didn't know if I had enough energy to sustain a whole lifetime with Asperger's syndrome but gradually I have begun to

Groupwork Vol. 24(2), 2014, pp.xx-xx. DOI: 10.1921/7501240203 
Jackie Martin, Katrina Fox, Duncan MacGregor and Laura Hickman

accept that despite everything being hard work I can still gain some enjoyment from it and I am lucky to be surrounded with understanding family and friends who don't mind if I'm being pedantic, or 'having a moment' and sitting on the floor with my hands over my ears. The acceptance I have had from those around me has helped me to accept myself and on the bad days we cry and get frustrated and angry and on the good days we laugh and joke about my idiosyncrasies. My Grandad always says not to worry about things we can't change and I try my best to adopt that approach to living with Asperger's syndrome, I can't change how it affects me so I might as well accept it.

Laura: I do think that I wouldn't be the person I am today without it (Asperger's syndrome), as I wouldn't be as understanding of different people as my own life experiences of not being accepted have made me understand what it is to not be accepted and realise that everybody deserves a chance in life. There are lots of positives about having Asperger's but sometimes it is hard to see the positives as you get overwhelmed with the negatives. The main negative is anxiety and sometimes because you look alright, people give you too much to do socially and you fail at it because you can't follow it. Another positive is that when you have got an interest, you tend to concentrate on it and get very good at it. I am good at geography and history and I have a very good memory for facts.

Group members believe that there is no one experience that is 'having Asperger's syndrome'. They believe that it is hard to define as there is no standard experience and each person feels differently. What unites the group members is the sense that people with Asperger's syndrome are often misunderstood and they believe that they have found understanding and acceptance in the group.

Diagnosis has been important for Laura, Duncan and Katrina as it has helped clarify why they struggle in certain areas. This clarity has helped them to understand themselves and has opened doors to help and support. However, diagnosis does not define individuals with Asperger's syndrome. Diagnosis does explain some of the difficulties they experience in a world which is organised by and for neuro typical people. They are all individual people and all have individual personalities. They do not want to be defined by diagnosis or by the assumptions that people make about them. They want to be defined as individuals and by the strengths and weaknesses they have as individual people. What they share is the experience of living in a world of neuro typical people where they do not feel included. 


\section{The original purpose for the group}

The work that the group was initially engaged in was the research project to find out what support people with Asperger's syndrome wanted from services. The group designed and piloted a questionnaire then sent out the questionnaires and analysed the data. Further questions were then designed based on this data. Focus groups and individual interviews were then held to explore the further questions. The interviews and focus groups were then transcribed and this data was analysed. Finally, the group presented the findings at a conference, which was organised by group members.

\section{How this article has been written}

The group worked on this article in same way that it conducts all of its work. It met a number of times, reflected on the success of the group, why it is successful and what the benefits have been to individual members. The ideas were written down so everyone could read them, and they were used to form our first draft. The article was then given some shape, sent out to all members and they commented on it and any comments were included in the final version. The reflections that are shared here are what the group believes was important about their groupwork.

\section{What made the group successful?}

The group identified two main reasons why it was successful. The first is related to the shared values of the group and the second is related to the way the group was organised.

\section{Shared values}

Drumm (2006) highlights 'inclusion and respect' as factors in making up a social work group. Whilst the ACG does not regard itself as such, Drumm's principles equally apply to this group. Drumm (2006) states: 
Jackie Martin, Katrina Fox, Duncan MacGregor and Laura Hickman

Groups validate every person's voice and honour each participant's view by exemplifying faith and belief in each individual's capability of constructive contributions. (p. 5)

The group believes that trust in each other and in the group as a whole was fundamental to the validation of every member. Trust within the group is the foundation on which it is built. Group members trust each other in a number of ways. There is trust that no one will be judged when they share their experiences. There is trust that no one will be pushed into doing things that they are not comfortable with or at a time which isn't right for them. There has been trust that members are able to complete tasks that are agreed and completed individually. There is trust in each other's skills and ability to fulfil individual roles. The trust within the group has meant that confidence has grown in all group members. The group members believe that without the trust that was established it would have been impossible to have been such a successful group.

Trust was built up as every group member shared the motivation to make a positive contribution to the lives of other members in the group and of people with Asperger's syndrome more widely. It was the willingness to share experiences and be open to each other's ideas which enabled the group to work very creatively. Kurland and Salmon (1993) as cited by Preston-Shoot (2007) refer to groupwork's

unique potential to help members learn and benefit from diversity, difference and commonality, to overcome the impact of stereotypes and to experience group processes as a powerful dynamic for change. (p.11)

As a result of the trust in the group, members were able to learn from each other. The formation of the group itself was a challenge to stereotypes and it was this challenge and the confidence that was placed in all members that enabled trust to grow. The group believed in itself and that it would succeed and the tone was set for this by the regarding of each member with Asperger's syndrome as 'expert'.

\section{Viewed as experts}

In the experience of group members, groups they had previously been a part of had not allowed for them to be involved in decision making. 
Most groups have a leader who controls the direction of the group whereas this group has operated on a more democratic basis. Group members felt they 'got off to a very good start' because Jackie discussed with them the idea that they were the 'experts'. All three members of the group with Asperger's syndrome feel that this group is the first time they have been regarded as and treated as experts. Group members' usual experience is that people who don't have Asperger's syndrome often think they have the authority to tell them what to do and sometimes that has led to feelings of insecurity.

Group members feel that the fact that they were regarded as the experts set the tone for the professional way in which all members conducted themselves. Group members believe that they behaved professionally in terms of how the group interacted with each other and how they conducted the meetings. The expertise of the group members lay in the group's individual experiences and the ability to use these analytically to add depth to the research. In most professional situations there are strict boundaries which inhibit the sharing of personal experiences, but in the case of this group sharing personal experiences has proved to be beneficial and essential to the group's success. One example of this is when participants expressed that they had experienced being misunderstood by others; group members were able to relate their own experiences of this which heightened the importance of this for people with Asperger's syndrome. The group feels that it has maintained a balance of acting professionally whilst providing a supportive environment for sharing relevant experiences. They have been able to share personal and occasionally upsetting situations because of the trust and boundaries that were established earlier on in the group. The importance of 'values and vision' in groupwork has been highlighted by Benson (2010) who points out that values 'motivate behaviour' (p. 119). This was certainly the experience of this group with the belief that adults with Asperger's syndrome could work together as a group and were the experts in their own experience setting the vision for what could be and has been achieved.

\section{Motivation and ambition for the group}

The motivation of each member for joining the group was linked to their view of Asperger's syndrome. The common theme between all 
four participants was the opportunity to be part of a group where adults with Asperger's syndrome had the opportunity to succeed in a group situation. Prior to the first meeting, Jackie met with the other three members individually and discussed what the purpose of the group would be. Part of Jackie's motivation for forming the group was to prove that adults with Asperger's syndrome could work collaboratively. It wasn't until the first meeting that the other members articulated their own motivations for joining the group. Although group members were united in their ambitions for the group, they joined for quite different reasons. In the first initial meeting, group members introduced themselves and spent some time getting to know each other. Part of this was sharing their motivations. Group members reflect on this initial discussion and their subsequent experience in the group:

Duncan: I was attracted to the group because it presented a different kind of problem. It would be dealing with qualitative data not quantitative. The group took me out of my comfort zone and I feel a more rounded person as a result. It gave me new experiences and the opportunity to hear other people's points of view. During this research I was treated as an expert whereas in previous research I had been involved in I felt I was treated as a guinea pig.

Katrina: my initial expectations of the group were quite low. I had never had any positive experiences working with others. I joined the group because I wanted the opportunity to use my experiences to help others and I was excited about challenging myself academically and putting my ability to think deeply to good use. In the first meeting I was quite reserved and had a negative viewpoint about having Asperger's and about myself. The time I have spent with the group has helped me to discover a different perspective on having Asperger's and I have become more accepting of myself. The group has become a strong unit that can produce good work but we have also become friends.

Laura: I wanted to be involved because I wanted to have a good opportunity to interact with people with Asperger's. I wanted to be part of something unique and something which could make an impact. I wanted to be given the opportunity to be an equal part of a group as I didn't think I had experienced this before. Previously I had been given boundaries which I couldn't adhere to. In the group I was a part of the decision making which agreed our boundaries and so for the first time I felt able to be fully part of a group. In the past I have felt pressured to say what other 
people wanted me to say whereas in this group I have been able to be myself and say what I really think.

\section{Roles}

Benson (2010) comments that each role within a group 'has a measurement of worth' (p. 53). Roles within this group weren't so much assigned as evolved. In the early stages of the groupwork, group members had a discussion about their individual involvement in the group and established what each member felt comfortable to contribute. This meant that all roles were occupied by the person who valued it for themselves. These were not initially formalised as roles but rather activities which each member felt comfortable to take part in. Over time, the group recognised that each member did perform a unique function in the group and this led to the group recognising these as 'roles' and creating 'nicknames' for each member, to reflect the part they played in the group. Duncan was nicknamed the 'data guy' and utilised his skills with numbers to complete the data analysis. He was an integral part of the group's discussions and used his experience to highlight barriers that society creates for people with Asperger's syndrome. Laura joined the group a little later than the other members. She became the group's 'enthusiast'. She brought a youthful enthusiasm to the group and a refreshing alternative perspective. She delivered 'pearls of wisdom' at unexpected moments and had a talent for relating the research findings to her own life experiences. Katrina was named the 'thinker' of the group as she was very good at conceptualising the ideas discussed in the group and found in the data. She also has a talent for articulating the ideas and suggested wording which captured the group's thoughts really well. Jackie was titled the 'navigator' by the group members as, in the view of the other three members, she enabled the group to achieve its full potential by using her faith in the group to uncover the group's valuable insights. She kept everybody on track and dealt with the practical elements of conducting research such as ethical approval, booking rooms and dealing with professionals outside of the group. These individual roles led to an effective group working experience as the varied experiences, insights and talents enabled the group to achieve its goals. When asked what individual group members contributed to 
the group, they said:

Duncan: I have a mathematical background which helped me make connections in the data when we analysed it and in a broader sense, connections in life. Part of my personal philosophy of life is that everything is connected and the challenge is trying to find those connections. This outlook has helped in this research, especially when we were having discussions about the data and making links between what different people said.

Katrina: My role as 'the thinker' came from my natural ability to think things through and my articulacy enabled me to communicate ideas into more understandable messages. I have always enjoyed using these skills but after finishing school I found it hard to find meaningful tasks in which I could use these skills and they got forgotten. I have thoroughly enjoyed my role within the group and I have enjoyed watching other group members put their own natural talents to good use. It has been a wonderfully pleasant experience to work in an environment where I can contribute in a manner which accommodates my needs and respects my boundaries. I have found that I can produce my best work when supported in this way. I have also enjoyed the opportunities that this project has brought me, I transcribed data and I assisted with focus groups. I have found working in this group has provided me with the chance to use my existing talents but it has also given me the freedom to test my own boundaries in a safe, supportive environment and because of this I feel I have learnt new skills and my faith in my own future has been restored.

Laura: I hope I brought to the group the understanding of how important the research and the group was and I hope I showed that I was very enthusiastic. I hope that I have shown the group how great they all are. I feel very proud to be a part of it. I think one of the good things about the group is that we can relate to each other. When we were looking at what people had said, I could see where they were coming from as I could relate to what was said.

Jackie: As the only neuro-typical member of the group, I tried to bring a sensitivity to the other members which I knew from discussions they didn't always experience. I believed that the group could work and it was up to us to find out how to work well together. Part of what I hope I brought to the group was the ability to bring together the valuable insights which came out of discussions and to ask questions in a way which enabled rich reflections. 
The move away from more traditional roles, such as 'leader' worked well for the group as it was important that all felt in control of the group's work, especially in the light of previous negative experiences.

\section{Boundaries}

Preston-Shoot (2007) discusses the importance of having an open discussion of power in group situations. In this group this was partly achieved through discussions about boundaries within the group. Each person was able to articulate their own individual boundaries and also determine the group's boundaries. Personal boundaries were defined partly by people's roles within the group as well as by what they felt comfortable with. Each member of the group respected the opinions, views and experiences of other team members which allowed a special trust to grow within the group, meaning that members felt comfortable enough to share personal and sometimes uncomfortable life experiences. Respecting each other's boundaries was an important part of the group success. For Duncan, it was important that he could state when he was not comfortable to take part. He chose not to take part in interviews and used the time instead to concentrate on data analysis. For Katrina, it was also important that she had the right to say 'no'. Important to her was also the lack of pressure to do something she is academically capable of but not emotional comfortable with. For Laura, it was important that she only shared what she felt comfortable to, but she found that she shared more of her own personal experience as she felt that she was understood and not judged: people were willing to listen and connect. In this way, each member had the power to contribute in the way that they wanted to and this was always respected by other members.

The group discussed in its very first session the importance of group boundaries, ensuring that everyone was comfortable with these. One example of this was the format of each session. Each session commenced with group members creating a list of what needed to be achieved. This created a clear plan to work to and enabled members to know what would be happening throughout the session. The tasks were then divided up into morning and afternoon sessions. The group also

Groupwork Vol. 24(2), 2014, pp.xx-xx. DOI: 10.1921/7501240203 
Jackie Martin, Katrina Fox, Duncan MacGregor and Laura Hickman

broke for lunch at the same time every meeting. This made the sessions predictable and easier for group members.

There were boundaries concerning the nature of the group to be considered and whether it had an open or closed membership. Although this was not discussed at the outset of the group, the discussion became necessary following the focus groups when some people wanted to join. A unanimous decision was made to keep the group as a closed membership. This decision was made because it was felt that the size of the group should remain the same. Members of the group felt that the addition of more people would compromise the quality of work that members would be able to contribute and would lead to members feeling over stimulated and hence, overwhelmed. This is especially important to people with Asperger's syndrome as over stimulation can lead to anxiety. Group members were very open about what worked well for them in the group as well as being aware of potential barriers to working well together.

\section{Working style}

The working style of the group was informed by the group's values. The desire to work in a way that suited everyone in the group meant that a working style evolved rather than being set by anyone at the commencement. At the beginning of each meeting group members shared any relevant news, both group related and personal. In previous groups that the members had experienced, personal matters were kept outside of the group. They found that sharing personal experiences was a better way of working as it meant that group members could support each other and tailor the responsibilities for the session accordingly. For example, if one group member had experienced something that was difficult for them to deal with, then allowances were made and someone else might take over the responsibility that they usually had. This enhanced the trust within the group and this in turn aided the quality of the work as members felt more able to contribute.

Part of the group's initial discussions at the beginning of each session was also used to create a 'to do' list. The separation of work into morning and afternoon sessions was important as this took account of the difference in concentration levels between morning and afternoon. 
The act of agreeing the structure of the work not only allowed effective working, it also ensured that each member felt comfortable and in control.

\section{How the group's working style evolved}

Initially the group didn't have a firm idea of how to record sessions. The group made notes on flipchart paper and then Jackie would type them up and bring them to the next meeting for approval from the group. If anyone wasn't able to attend then they were contacted via email and forwarded the notes. This enabled everyone to feel involved at all stages.

As the confidence of the group grew, an agreed working method evolved. The group stopped using flipchart paper and started to type notes directly onto a laptop. Group members took turns to record meetings in this way. This allowed for a better degree of accuracy as it eliminated the need for Jackie to translate her notes into a summary document. The group always re-read and checked the notes to ensure that all members of the group were happy with what was written. If someone was unhappy with the way in which something was recorded, the group would discuss alternatives and decide how best to re-write it. All of the group's notes were agreed upon either in person or email or sometimes both.

The way the group worked together allowed for individual circumstances as well as preferences. As it met on a voluntary basis, this sometimes meant that people couldn't attend. The trust that was established within the group enabled individuals to complete some work on their own and then submit it to the group for approval. Some tasks had to be completed separately as they were specific to a person's skill set and personal boundaries, for example Duncan analysed the data whilst the other group members conducted interviews and focus groups. Work that was done individually was then brought back to a group meeting for the approval of all group members.

\section{How was the group successful?}

How to measure the success of a group? Drumm (2006) states that an effectual group 'creates norms and develops its own culture' (p. 6). By

Groupwork Vol. 24(2), 2014, pp.xx-xx. DOI: 10.1921/7501240203 
this definition the group certainly was effectual. The group's ability to set its own working style and each member assign themselves the roles they were comfortable with set the norms and culture. This had led to group members expressing that they feel safe within the group. They identify that this security has been established with boundaries and trust but also with specific things like considering how they speak to each other. One example of this is avoiding the use of metaphors and sticking to a precise time schedule, starting, ending and breaking at the same time. Creating this predictability and structure has contributed to the group's sense of security and enabled members to feel calm and relaxed which in turn has enabled members to concentrate on the relevant task. The group is respectful of the individual member's strengths and preferences. Individual members feel comfortable asking for help and clarification as there is no judgement within the group. The members of the group feel able to discuss things that they would feel uncomfortable discussing elsewhere. This is due to the understanding and empathy that they receive from group members. As part of the reflection for this article the group discussed the theme of self consciousness as adults with Asperger's syndrome and came to the conclusion that they feel less self conscious within the group even though the topic of conversation centres around having Asperger's syndrome. This is a testimony to the power of groupwork processes and what can be achieved when processes are value informed.

The attention to practical matters has also been an element which has contributed to the group working well. One example of this has been the location of the meetings. During the $\mathrm{PhD}$ phase of the research the group had funding to provide a quiet, private room. They felt that having a private space allowed the group to develop its own rules, boundaries and working style and it enabled us to concentrate without distraction. The group decision to continue beyond the PhD phase meant that finding an appropriate, quiet, affordable place to meet was paramount. As with all decisions the location was discussed and a decision was made that suited all group members. The group now meets in a local library. This does sometimes lead to difficulties as there are many distractions with other groups also meeting in an open space. Consideration has to be given now to where group members sit as facing in a particular direction can provide too much sensory stimulation and so make concentrating on the task in hand difficult! The fact that there 
is trust between members means that this can be addressed openly and seating arranged to suit everyone.

The group measures its own success by how individuals feel within and about the group. Group members have been able to create a group environment in which they have developed the group rules. This has meant that group members have been able to share their experiences. They often experience anxiety in sharing experiences in other contexts. Having control of the group processes has meant that members have been calmer. They have felt there have been no unwritten social rules other than those that have been created by the group. Some of the key things that have enabled members to feel so positive are; confidentiality 'what's said in the group stays in the group', acceptance of each other and the validity of experiences and empathising with each other, a skill which those with Asperger's syndrome are often said to struggle with. In the experience of group members, social situations require a lot of physical and emotional energy. Being in this group requires less energy as anxiety is minimised as group members have control over what happens in the group and trust that if something unexpected happens, they would have the support from other group members to deal with it. This means that the energies of group members can be channelled to the task in hand. There have been occasions where due to personal circumstances people have not felt able to fulfil their usual role in the group. The group adapted to this and other people took on the role to support that person.

\section{Groupwork success and Asperger's syndrome}

The positive experiences that have been had in the group have shown members that group work can be highly successful for people with Asperger's syndrome. They have not only succeeded in the tasks that they set out to achieve but have gained strength, both collectively and individually. The group planned and executed a conference that over a hundred people attended and each member of the group was able to speak with confidence and authority about the groupwork. All group members felt they would be unable to achieve this prior to joining the group. The success that was evident at the conference has had a lasting effect on the self assurance of each group member and has encouraged and motivated us to continue with our work.

Groupwork Vol. 24(2), 2014, pp.xx-xx. DOI: 10.1921/7501240203 
Group members believe that it is their Asperger's syndrome that has made their group successful. It is successful because they have Asperger's syndrome, not in spite of it. They believe that their common identity has given them a common frame of reference. Although they have different opinions, they have all experienced the same kind of prejudices. They all have the same motivation to help other people with Asperger's syndrome and to have a positive approach to it. The group is unusual (at least in the experience of its members) as although it has met very regularly for over three years, there has never been any conflict between group members. The group members believe that this is because they respect and listen to each other and trust each other. There is no struggle for control as all decisions are taken democratically and everyone's views are always accommodated. Group members in fact commented that they acted differently in this group than in any groups they had previously been a part of. Some are quieter as they are usually strong personalities who do not feel the need to exert themselves and one is more confident and able to speak out, which is in contrast to previous experience. In their previous experience as group members, they hadn't been taken seriously because they have Asperger's syndrome whereas in this group this is the very reason they are taken seriously. They do not feel 'odd' in this group whereas they had felt this in previous group situations. In previous groups, the sharing of experiences had been accompanied by an expectation of the expression of emotions, whereas in this group, experiences were discussed in a 'matter of fact' way and this has suited group members. In short, group members had experienced arrogance and ignorance outside of this group and it is the lack of these and the experience of acceptance that has allowed each member to contribute to as well as benefit from the group. One member says that the group is 'as the world should be'. Where people are accepted, they can reach their potential and it is in group situations that people either find acceptance or prejudice. Laura sums up why the group was important to her:

For me the group was special because I hadn't worked in this way before and it was very unique because of how nice a group it was and everyone was considerate of each other's feelings and needs. The work was very special because out of all the things in my life, probably the most relevant one would be my Asperger's and the group gave me the chance to really think about what it means to have Asperger's in a calm environment where I could concentrate and not feel judged. 


\section{References}

Attwood. T. (2007) The Complete Guide to Asperger's Syndrome. London Jessica Kingsley Publishers

Baron-Cohen, S. (1995) Mindblindness: An Essay on Autism and Theory of Mind. Massachusetts, The MIT Press

Benson, J. (1997) Working More Creatively with Groups, Third Edition. Abingdon, Oxon, Routledge

Brown, S., Garvey, T. and Harden, T. (2011) A Sporting Chance: Exploring the connection between social work with groups and sports for at-risk urban youth. Groupwork, 21, 3, 62-77

Drumm, K. (2006) The Essential Power of Group Work. Social Work with Groups, 29, 2, 17-31

Kurland, R. and Salmon, R. (1993) 'Groupwork versus casework in group'. Groupwork, 6, 1, 5-16

Preston-Shoot, M. (2007) Effective Groupwork, Second Edition, Basingstoke, Palgrave Macmillan

Wing, L (1991) The relationship between Asperger's syndrome and Kanner's autism. in U. Frith (Ed) Autism and Asperger Syndrom, Cambridge, Cambridge University Press 